\title{
KOMBINASI CAMPURAN LIMBAH KAYU DAN NON KAYU UNTUK BRIKET SEBAGAI BAHAN BAKAR ALTERNATIF
}

\author{
oleh: \\ SUROTO HS ${ }^{1}$ ) \\ JANTRI SIRAIT ${ }^{2}$ )
}

\begin{abstract}
Berdasarkan pengalaman dari proses moulding limbah yang diperoleh mencapai $25 \%$ dari volume kayu yang diolah. Jika kayu yang diolah sekitar $100 \mathrm{~m}^{3}$ per hari maka akan diperoleh limbah sekitar $25 \mathrm{~m}^{3}$. Jika dalam satu bulan bekerja 25 hari maka akan diperoleh limbah sebesar $625 \mathrm{~m}^{3}$. Jika diasumsikan hasil samping tempurung kelapa sebesar 10\% dengan rata-rata produksi kelapa di Kaltim sebesar $1.195 .68 \mathrm{~kg} / \mathrm{Ha}$ maka diperkirakan hasil samping tempurung kelapa sebesar $119,57 \mathrm{Kg} / \mathrm{Ha}$. Batubara saat ini merupakan hasil tambang yang potensial penghasil pendapatan asli daerah. Penggunaan utama batubara saat ini sebagai penghasil energi, namun pada sisi lain sebagian dimanfaatkan untuk briket batubara. Asal bahan baku briket saat ini kebanyakan masih dalam bentuk tunggal (batubara, tempurung kelapa dan arang kayu). Dalam penelitian ini akan mengkombinasikan bahan limbah serbuk arang kayu, tempurung kelapa dan batubara. Hasil menunjukan kualitas briket tunggal dengan parameter nilai kalor berturut-turut $5.419 \mathrm{cal} / \mathrm{g}$ bengkirai $(B), 5.324 \mathrm{cal} / \mathrm{g}$ batubara (Bb), 4.356 $\mathrm{cal} / \mathrm{g}$ tempurung kelapa (Tk), $4.126 \mathrm{cal} / \mathrm{g}$ ulin (U), dan $4.087 \mathrm{cal} / \mathrm{g}$ meranti (M). Sedangkan kualitas kombinasi campuran dengan parameter nilai kalor berturut-turut $4.876 \mathrm{cal} / \mathrm{g} \mathrm{BBb}$, $4.868 \mathrm{cal} / \mathrm{g}$ BTk, $4.783 \mathrm{cal} / \mathrm{g}$ UMB, $4.760 \mathrm{cal} / \mathrm{g}$ BTk, $4.477 \mathrm{cal} / \mathrm{g}$ UTk, $4.454 \mathrm{cal} / \mathrm{g}$ UB, 4.221 $\mathrm{cal} / \mathrm{g}$ BTk, $4.162 \mathrm{cal} / \mathrm{g} B M, 4.156 \mathrm{cal} / \mathrm{g} \mathrm{MBb}$, dan $4.039 \mathrm{cal} / \mathrm{g}$ UM. Bila dibandingkan dengan standar nilai kalor yang dipersyaratkan secara nasional dan internasional masih belum memenuhistandar.
\end{abstract}

Kata kunci : Limbah Moulding, Tempurung kelapa, Batubara dan Briket

\section{PENDAHULUAN}

$\mathrm{P}$ ada proses pengolahan kayu di industri moulding selain menghasilkan produk utama kusen, panel pintu dan daun jendela juga menghasilkan limbah berupa potongan kayu, serutan, tatalan, serbuk gergaji dan debu kayu. Adanya limbah akan menimbulkan masalah, penanganannya yang selama ini dibiarkan membusuk, ditumpuk dan dibakar yang kesemuanya akan berdampak negatif terhadap lingkungan sehingga penanggulangannya perlu ditangani. Berdasarkan pengalaman dari proses moulding limbah yang diperoleh mencapai $25 \%$ dari volume kayu yang diolah. Jika kayu yang diolah sekitar $100 \mathrm{~m}^{3}$ per hari maka akan diperoleh limbah sekitar $25 \mathrm{~m}^{3}$. Jika dalam satu bulan bekerja 25 hari maka akan diperoleh limbah sebesar $625 \mathrm{~m}^{3}$. Pemanfaatan limbah moulding dapat mengurangi dampak negatif terhadap lingkungan seperti pencemaran air, pencemaran udara, dan lainnya. Selain mengurangi dampak terhadap lingkungan, akan berdampak positif terhadap kesempatan lapangan kerja bagi masyarakat apabila dimanfaatkan dengan bijak. Tanaman kelapa hasil utama yang dimanfaatkan adalah daging buah kelapa yang dimanfaatkan untuk kopra dan santan kelapa. Pada proses pengolahan buah kelapa, hasil samping adalah sabut kelapa, tempurung kelapa dan air buah kelapa. Apabila hasil samping dari proses pengolahan tidak ditangani dengan benar akan menimbulkan dampak terhadap lingkungan. Potensi kelapa di Indoensia seluas 3.712 juta $\mathrm{Ha}$ terdiri dari $96,6 \%$ perkebunan rakyat, $2,7 \%$ swasta dan $0,7 \%$ milik negara (Setiadji B, 2006). Luas tanaman kelapa yang menghasilkan dikaltim seluas $37.385,00 \mathrm{Ha}$, dengan rata-rata produksi sebesar 1.195 .68 $\mathrm{kg} / \mathrm{Ha}$ (Dinas Perkebunan Provinsi Kalimantan Timur, 2004). Jika diasumsikan hasil samping tempurung kelapa sebesar $10 \%$ maka diperkirakan hasil sampingnya adalah $119.5680 \mathrm{~kg} / \mathrm{Ha}$. 
Potensi sumber daya batubara Indosenesia diperkirakan mencapai 57,85 miliar ton, terdiri dari 20,53 miliar ton dikatagorikan terindikasi, 12,47 miliar ton sumber daya terukur dan 6,98 miliar ton kategori cadangan. Sedangkan untuk Kaltim sekitar $52,15 \%$ dari potensi tersebut dan sisanya tersebar di Sumatera, Jawa, Sulawesi dan Papua (PT. Komunitas Bangun Pertama, 2007). Pada proses pengolahan batubara ada yang berkualitas ekspor dan ada yang non ekspor (rejek). Salah satu cara penanganannya adalah memanfaatkan limbah tersebut untuk briket. Briket merupakan arang yang diolah lebih lanjut menjadi bentuk briket (penampilan dan kemasan yang lebih menarik) yang dapat digunakan untuk keperluan energi sehari-hari. Pembuatan briket dari limbah industri pengolahan kayu dilakukan dengan cara penambahan perekat tapioka. Di mana bahan baku diarangkan terlebih dahulu kemudian dihaluskan dengan ukuran diameter $3-5 \mathrm{~mm}$ dicampur dengan perekat, diaduk dengan mixer kemudian dikempa dengan mesin pres secara hidrolik atau dengan pres secara manual. Agar dari ketiga sumber daya alam tersebut berdayaguna dilakukan pembuatan briket kombinasi campuran ketiga bahan baku briket tersebut.

\section{BAHAN DAN METODA}

\section{Bahan dan Peralatan}

Bahan yang digunakan pada pembuatan briket antara lain serbuk gergaji, tatalan kayu, tempurung kelapa, batubara, tepung tapioka, dan air. Sedangkan alat yang digunakan antara lain drum karbonisasi, hammer mill, press, cetak briket, mixer, gelas beaker, timbangan, shacker, pengaduk, dan kompor.

\section{Rancangan Penelitian}

Rancangan penelitian yang digunakan dengan mengkombinasikan beberapa jenis limbah Moulding, tempurung kelapa dan batubara. Adapun kombinasi campuran adalah pada Tabel 1.

Tabel 1. Kombinasi Campuran Briket

\begin{tabular}{|c|l|}
\hline No. & \multicolumn{1}{|c|}{ Kombinasi } \\
\hline 1 & Ulin (U) \\
\hline 2 & Bengkirai (B) \\
\hline 3 & Meranti M) \\
\hline 4 & Tempurung kelapa (TK) \\
\hline 5 & Batubara (Bb) \\
\hline 6 & Ulin + Meranti (UM) \\
\hline 7 & Meranti + Batubara (MBb) \\
\hline 8 & Bengkirai + Batubara (BBb) \\
\hline 9 & Ulin + Bengkirai (UB) \\
\hline 10 & Ulin + Tempurung kelapa (UTk) \\
\hline 11 & Meranti + Tempurung kelapa (MTk) \\
\hline 12 & Batubara + Tempurung kelapa (BTk) \\
\hline 13 & Bengkirai + Meranti (BM) \\
\hline 14 & Bengkirai Tempurung kelapa (BTk) \\
\hline 15 & Ulin + Meranti + Bengkirai (UMB) \\
\hline
\end{tabular}

\section{Tahap-tahap percobaan}

1. Pengumpulan bahan baku berupa limbah Moulding, tempurung kelapa, batubara dan tepung tapioka dan batubara

2. Limbah serbuk gergaji dan tatalan dari moulding, tempurung kelapa, dan batubara dijemur untuk mengurangi kadar air yang terikat.

3. Limbah berupa tatalan dan serutan, dimasukan ke dalam drum karbonisasi kemudian dilakukan penyalaan dan perhatikan, apabila telah menyala sempurna maka dilakukan penutupan dipermukaan atas drum karbonisasi.

4. Tempurung kelapa, dimasukan ke dalam drum karbonisasi kemudian dilakukan penyalaan dan 
perhatikan, apabila telah menyala sempurna maka dilakukan penutupan dipermukaan atas drum karbonisasi.

5. Batubara, dimasukan ke dalam drum karbonisasi kemudian dilakukan penyalaan yang terlebih dahulu disiram dengan minyak gas secukupnya, dan perhatikan, apabila telah menyala sempurna maka dilakukan penutupan dipermukaan atas drum karbonisasi.

6. Masing-masing arang limbah moulding, tempurung kelapa dan batubara dikeluarkan dari drum karbonisasi kemudian dikeringanginkan.

7. Penghalusan arang limbah moulding, tempurung kelapa dan batubara dengan menggunakan Hammer Millyang dilengkapi dengan saringan 60 mesh.

8. Saring dengan shacker dengan saringan 60 mesh untuk memperoleh keseragaman serbuk arang limbah mouding, tempurung kelapa dan batubara.

9. Penimbangan serbuk arang limbah moulding, tempurung kelapa, batubara dan tepung tapioka sesuai dengan perlakuan.

10. Tepung tapioka yang sudah timbang dimasukkan ke dalam beaker glas, tambahkan air secukupnya kemudian panaskan dengan kompor.

11. Pada saat pemanasan tepung tapioka dan air, diperhatikan kekentalan lem tapioka agar tidak terlalu kental untuk mempermudah proses pencampuran lem dengan serbuk arang.

12. Pencampuran lem dan serbuk dilakukan dengan mixer (adonan) secara homogen (tercampur dengan sempurna).

13. Masukan adonan bahan briket ke dalam cetakan briket.

14. Pencetakan briket dilakukan dengan menggunakan mesin pres dengan tekanan 15 bar, biarkan 15 menit, selanjutnya briket dikeluarkan dari cetakan briket dengan menggunakan mesin pres.

15. Pengeringan briket dilakukan dengan alat pengering (oven).

16. Adapun bagan alir proses pembuatan briket pada Gambar 1 berikut.

\section{PROSES PEMBUATAN BRIKET}

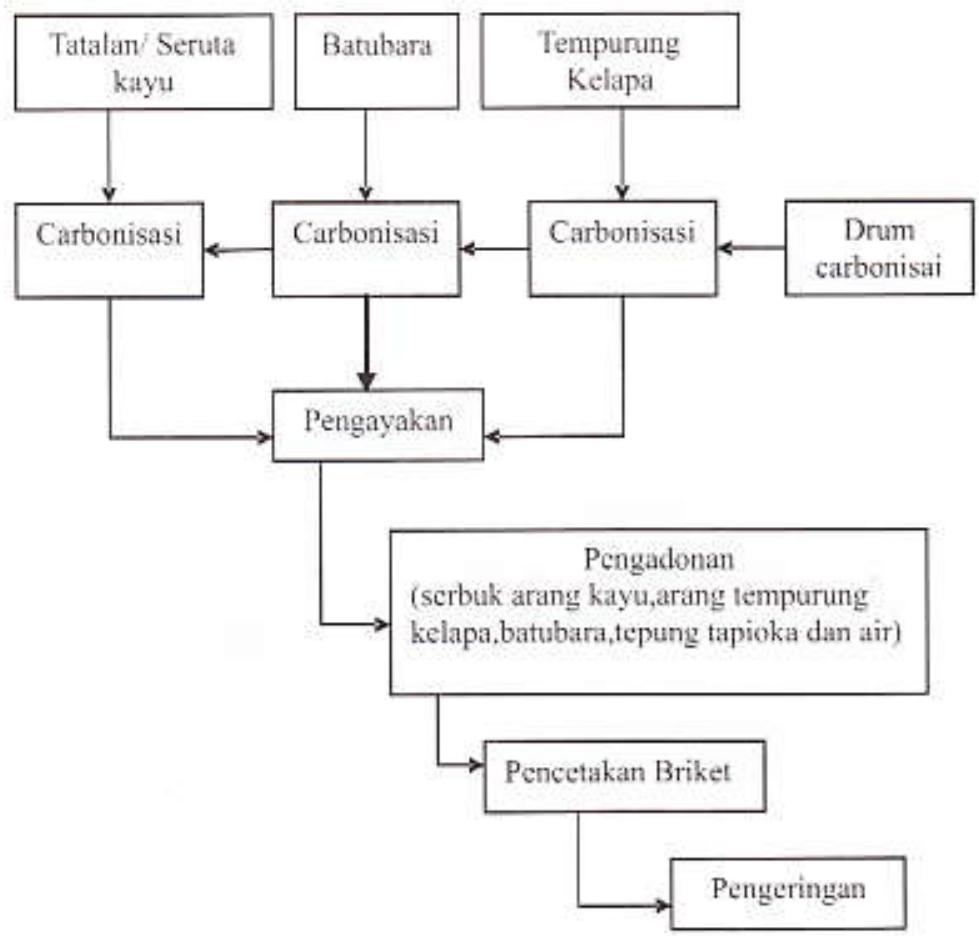

Gambar 1. Bagar Alir Proses Pembuatan Briket

Parameter yang akan dianalisa adalah kadar kalor briket 


\section{HASIL DAN PEMBAHASAN}

Hasil pengujian kadar nilai briket pada Tabel 2.

\begin{tabular}{|c|l|l|}
\hline No. & \multicolumn{1}{|c|}{ Kombinasi } & \multicolumn{1}{|c|}{ Nilai Kalor } \\
\hline 1 & Ulin (U) & $4.126 \mathrm{cal} / \mathrm{gr}$ \\
\hline 2 & Bengkirai (B) & $5.419 \mathrm{cal} / \mathrm{gr}$ \\
\hline 3 & Meranti M) & $4.087 \mathrm{cal} / \mathrm{gr}$ \\
\hline 4 & Tempurung kelapa (Tk) & $4.356 \mathrm{cal} / \mathrm{gr}$ \\
\hline 5 & Batubara (Bb) & $5.324 \mathrm{cal} / \mathrm{gr}$ \\
\hline 6 & Ulin + Meranti (UM) & $4.039 \mathrm{cal} / \mathrm{gr}$ \\
\hline 8 & Bengkirai + Batubara (BBb) & $4.087 \mathrm{cal} / \mathrm{gr}$ \\
\hline 9 & Ulin + Bengkirai (UB) & $4.454 \mathrm{cal} / \mathrm{gr}$ \\
\hline 10 & Ulin + Tempurung kelapa (UTk) & $4.477 \mathrm{ca} / \mathrm{gr}$ \\
\hline 11 & Meranti + Tempurung kelapa (MTk) & $4.221 \mathrm{cal} / \mathrm{gr}$ \\
\hline 12 & Batubara + Tempurung kelapa (BTk) & $4.868 \mathrm{cal} / \mathrm{gr}$ \\
\hline 13 & Bengkirai + Meranti (BM) & $4.162 \mathrm{cal} / \mathrm{gr}$ \\
\hline 14 & Bengkirai Tempurung kelapa (BTk) & $4.760 \mathrm{cal} / \mathrm{gr}$ \\
\hline 15 & Ulin + Meranti + Bengkirai (UMB) & $4.783 \mathrm{cal} / \mathrm{gr}$ \\
\hline
\end{tabular}

Berdasarkan hasil uji briket dari hasil penelitian pada tabel 2 menunjukkan bahwa nilai kalor yang dihasilkan secara berturut-turut untuk komposisi tunggal Bengkirai $5.419 \mathrm{cal} / \mathrm{gr}$. Batubara 5.324 $\mathrm{cal} / \mathrm{gr}$, Tempurung kelapa $4 . .356 \mathrm{cal} / \mathrm{gr}$, ulin $4.126 \mathrm{cal} / \mathrm{gr}$ dan meranti $4.087 \mathrm{cal} / \mathrm{gr}$ atau nilai kalor briket bebahan baku serbuk tunggal berkisar antara $4.087 \mathrm{cal} / \mathrm{gr}$ s.d. $5.419 \mathrm{cal} / \mathrm{gr}$. Untuk lebih jelasnya nilai kalor tungal dapat dilihat pada gambar 2. berikut;

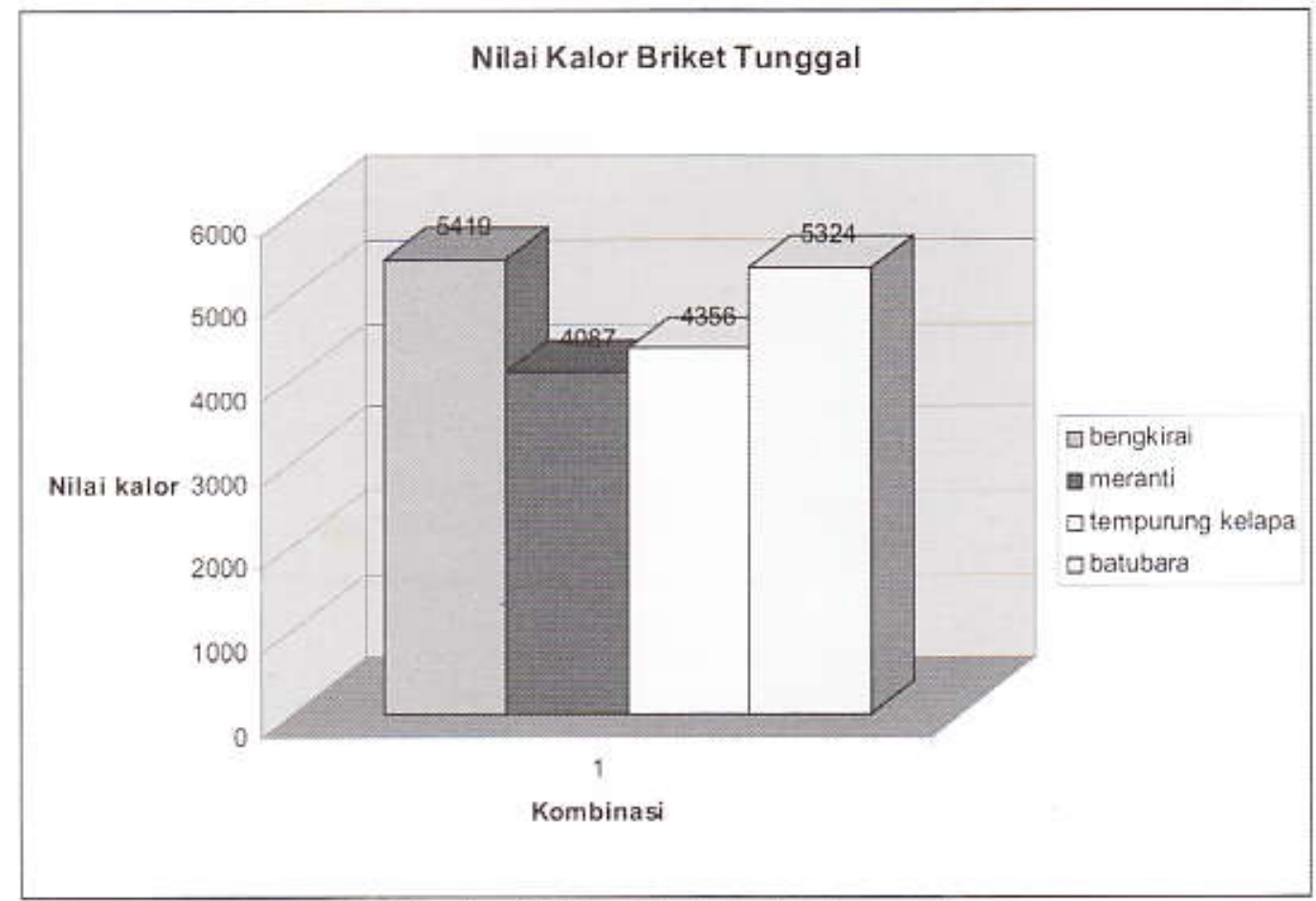

Gambar 2. Nilai kalor briket tunggal 
Nilai Kalor tertinggi briket tunggal terdapat pada Bengkirai diikuti Batubara, Tempurung kelapa, dan Meranti hal ini diduga bahwa bahan baku limbah moulding Bengkirai pada saat proses karbonsiasi terjadi secara sempurna dibanding dengan limbah moulding Ulin dan Meranti, hal ini juga disebabkan asal bahan baku ulin berupa serbuk dan meranti berupa serutan sehingga pada akhir proses karbonisasi sebagian besar terbentuk menjadi abu. Sedangkan batubara diambil dari hasil tambang rakyat yang nilai kalornya rendah, dan tempurung kelapa yang diambil masih muda. Suroto dkk (2008) mengatakan bahwa nilai kalor pellet dari bengkirai yang bahan bakunya tanpa dilakukan karbonisasi sebesar $4.310 \mathrm{cl} / \mathrm{gr}$ sedangkan nilai kalor briket bengkirai bila bengkirai dilakukan proses karbonisasi lebih dahulu sebesar $5.419 \mathrm{cal} / \mathrm{gr}$, sehingga terjadi kenaikan sebesar $1.109 \mathrm{cal} / \mathrm{gr}$. Nilai kalor pellet dari ulin dan meranti yang bahan bakunya tanpa dilakukan karbonisasi sebesar $4.380 \mathrm{cal} / \mathrm{gr}$ dan 4.287 sedangkan kalor briket ulin dan meranti bila dilakukan proses karbonisasi sebesar $4.126 \mathrm{cal} / \mathrm{gr}$ dan $4.087 \mathrm{cal} / \mathrm{gr}$, terjadinya penurunan kadar kalor diduga karena pada saat proses karbonisasi tidak terjadi secara sempurna sehingga yang terbentuk sebagian besar abu bukan arang, selain hal tersebut juga disebabkan karena ulin berupa serbuk, meranti berupa serutan.

Menurut Alpian (2003) mengatakan bahwa berbedaan nilai kalor dipengaruhi oleh berat jenis kayu, proses pengarangan, zat mudah menguap dan nilai kadar karbot terikat. Direktorat Jenderal Listrik dan Energi Baru (1991) bahwa pada dasarnya semua jenis pohon dapat dijadikan sebagai sumber energi, tetapi tiap-tiap jenis pohon mempunyai nilai kalor yang berbeda yang ditentukan oleh besar kecilnya berat jenis. Berat kayu berbanding lurus dengan nilai kalornya, semakin tinggi berat jenisnya semakin tinggi pula nilai kalornya, hal ini terjadi pada serbuk bengkirai.

Variasi nilai kalor dipengaruhi oleh kadar lignin dan zat ekstraktif, kadar lignin yang tinggi pada kayu akan mempengaruhi nilai kalor kayu tersebut, sedangkan kadar ekstraktif tergantung pada mudah dan tidak zat ekstraktif tersebut terbakar (Komarayati dan Gusmalina, 1994) serta Hudaya (1989) juga mengemukakan bahwa nilai kalor sangat dipengaruhi oleh kadar lignin dan zat ekstraktif. Kadar lignin yang tinggi akan meningkatkan nilai kalor hal ini terjadi pada briket arang yang terbuat dari Bengkirai.

Sudrajat (1983) mengatakan bahwa bahan baku, bahan perekat, dan tekanan pengempaan sangat berpengaruh terhadap nilai kalor briket arang yang dihasilkan.

Nilai kalor Birket batubara menempati urutan kedua setelah briket bengkirai dan nilai kalor briket tempurung menempati urutan ke tiga sebelum ulin dan meranti. Hal ini terjadi pada umumnya nilai kalor briket batubara lebih tinggi dibandingkan dengan tempurung kelapa, ulin dan meranti.

Ishlah T (2004) mengatakan bahwa endapan batubra di wilayah PT. Kaltim Prima Coal (KPC) dikelompokkan atas 2 kelas yakni batubara prima dengan nilai kalor $6.800 \mathrm{kal} / \mathrm{gr}$ dan batubara pinang dengan kalor $6.200 \mathrm{kal} / \mathrm{gr}$. Sedangkan di Berau daerah prospek sambarata dengan kalor 5 . 551 s.d. $5.956 \mathrm{kal} / \mathrm{gr}$, Lati $4.945 \mathrm{cal} / \mathrm{gr}$ s.d. $5.120 \mathrm{cal} / \mathrm{gr}$. Batubara yang mempunyai kalor rendah $4.000 \mathrm{cal} / \mathrm{gr}$ digunakan untuk PLTU dengan kebutuhan sebanyak 8.000 ton bulan. Menurut Haspiadi (2007) mengatakan bahwa nilai kalor batubara Kaltim berkisar antara $5.218 \mathrm{cal} / \mathrm{gr}$ s.d. $5.590 \mathrm{cal} / \mathrm{gr}$.

Sembiring FS(2009) mengatakan bahwa bahwa pasokan briket batubara diperkirakan hanya mencapai 90.000 s.d. 100.000 ton, sementara kebutuhan bisa mencapai 3,3 juta ton.

Untuk memenuhi kebutuhan briket bagi kepentingan industri kecil dan menengah saja diperkirakan tidak akan terpenuhi sebab tahun beerikutnya kebutuhan bagi industri bisa mencapai 300.000 ton, sedangkan kebutuhan rumah mencapai tiga juta ton. Harga briket yang semakin kompetitif ketimbang minyak tanah itu membuat produk briket semakin dicari industri maupun rumah tangga.

Industri seperti peternakan ayam, pabrik semen, genteng, dan batu bata semakinbriket, banyak yang menggunakan briket, demikian pula rumah tangga. Hingga saat ini pemanfaatan batubara sebagai sumber energi baru mencapai $14 \%$, sementara BBM $5 \%$, gas bumi $26 \%$ dan energi lainnya $6 \%$.

Briket tempurung kelapa merupakan bahan bakar alternatif yang terbuat dari bahan baku tempurung kelapa yang sudah diolah melalui proses karbonisasi, dilakukan penyerbukan, dan pengepresan sehingga terbentuk briket. Nilai kalor briket tempurung kelapa dari hasil penelitian 
sebesar $4 . .356 \mathrm{cal} / \mathrm{gr}$, ini lebih kecil dibandingkan dengan nilai kalor yang diproduksi PT. Marga Okapallo dengan nilai kalor $6.481 \mathrm{cal} / \mathrm{gr}$. Hal ini diduga pada saat proses karbonisasi dengan menggunakan drum yang dilengkapi dengan lubang-lubang didinding drum dan dan dilengkapi cerobong penutup drum akan menyebabkan pembakaran tidak terkontrol sehingga menyebabkan karbotn terikat banyak terlepas dan sebagian hasil pembakaran terbentuk abu. Sifat briket tempurung kelapa antara lain mudah terbakar, menghasilkan panas cukup tinggi, tahan lama dan tidak berbau.

Dua kombinasi campuran berturut-turut Batubara + Tempurung kelapa $4.868 \mathrm{cal} / \mathrm{gr}$ Bengkirai + tempurung kelapa $4.760 \mathrm{cal} / \mathrm{gr}$. Ulin + Tempurung kelapa $4.477 \mathrm{ca} / \mathrm{gr}$, Ulin + Bengkirai 4.454 $\mathrm{cal} / \mathrm{gr}$, Meranti + Tempurung kelapa $4.221 \mathrm{cal} / \mathrm{gr}$, Bengkirai + Meranti (BM) $4.162 \mathrm{cal} / \mathrm{gr}$, Bengkirai + Batubara $4.087 \mathrm{cal} / \mathrm{gr}$, dan Ulin + Meranti (UM) $4.039 \mathrm{cal} / \mathrm{gr}$ atau kadar kalor 2 (dua) kombinasi briket berkisar antara $4.039 \mathrm{cal} / \mathrm{gr}$ s.d. $4.868 \mathrm{cal} / \mathrm{gr}$. Tiga kombinasi campuran adalah Ulin + Meranti + Bengkirai (UMB) $4.783 \mathrm{cal} / \mathrm{gr}$. Untuk lebih jelasnya dapat dilihat pada Gambar 3 berikut;

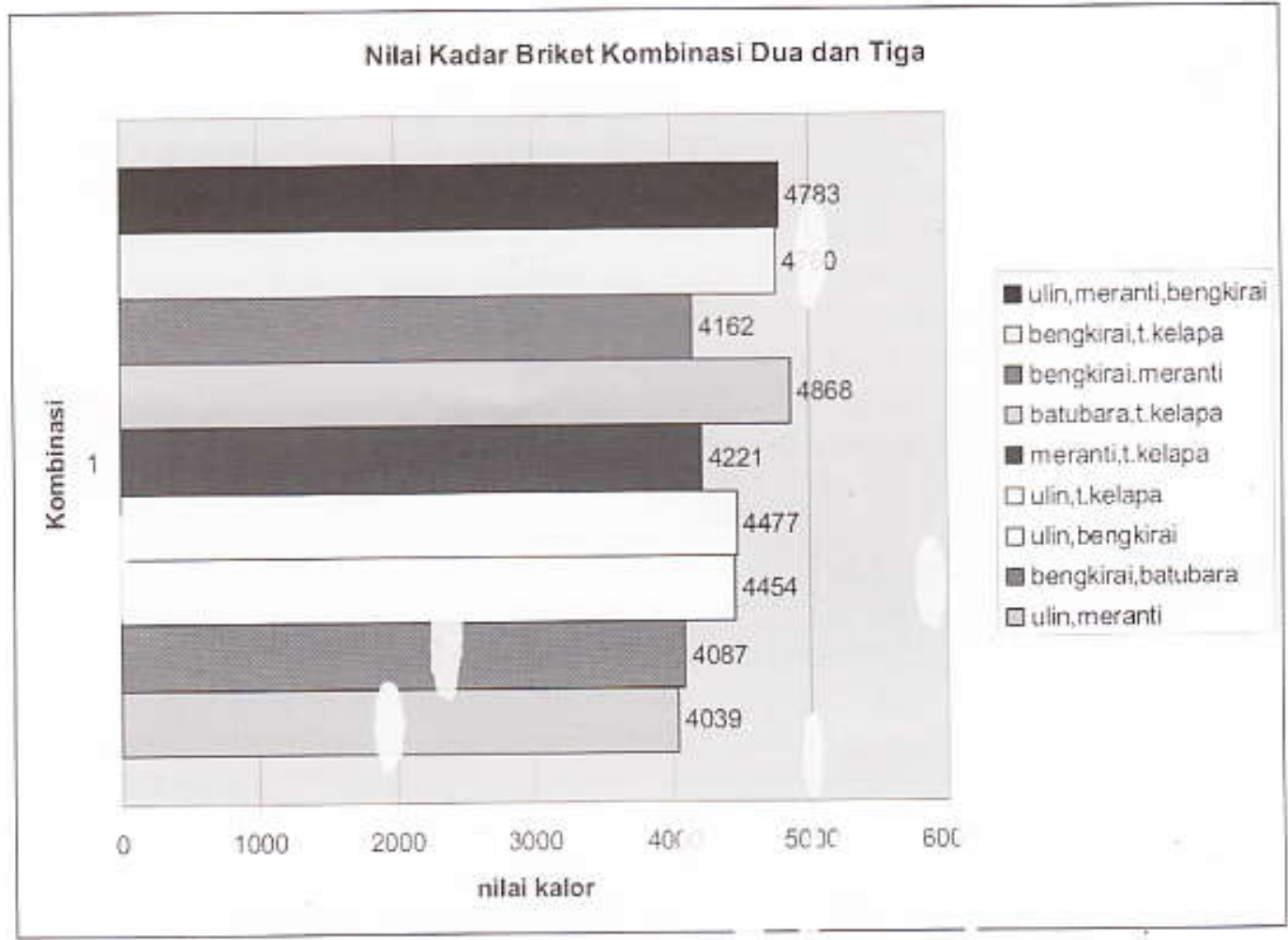

Gal jar 3. Nilai kalor briket kombinasi 2 (dua) de 3 (tiga).

Untuk meningkatkan nilai kalor briket Meranti dan Tempurung ke apa dapat dikombinasil n dengan arang Batubara, Bengkirai, dan Ulin, dengan urutan nilai kalo $\mathrm{Bb}+\mathrm{Tk} 4.868 \mathrm{cal} / \mathrm{gr}$, E + Tk $4.760 \mathrm{cal} / \mathrm{gr}, \mathrm{M}+\mathrm{Tk} 4.221 \mathrm{cal} / \mathrm{gr}, \mathrm{M}+\mathrm{B} 4.162 \mathrm{cal} / \mathrm{gr}, \mathrm{U}+$ Tk $4.477 \mathrm{c} \mathrm{s} / \mathrm{gr} \mathrm{dan} U+\mathrm{B} 4.454 \mathrm{cal} / \mathrm{gr}$ dan $\mathrm{U}+\mathrm{B}+\mathrm{M} 4.783 \mathrm{cal} / \mathrm{gr}$.

Nilai kalor briket tunggal bengkirai, batubara dan tempurung menduduk urutan peringkat 1,2 dan 3 sedangkan nilai kalor Ulin dan Meranti menduduki urutan peringkat 4 dan 5 . Dengan rendahnya nilai kalor ulin dan meranti maka untuk meningkatkan nilai kalor di kombinasikan dengan aran Bengkirai, Batubara dan Tempurung kelapa. Terjadi peningkatan nilai kalor Meran Ulin,Tempurung kelapa setelah dikombinasikan dengan arang Batubara, Bengkirai dan de Tempurung kelapa berturut-turut $75 \mathrm{cal} / \mathrm{gr}, 134 \mathrm{cal} / \mathrm{gr}, 351 \mathrm{cal} / \mathrm{gr}, 328 \mathrm{cal} / \mathrm{gr}$, dan $404 \mathrm{cal} / \mathrm{gr}$. Adanyu peningkatan nilai kalor briket ini diduga karena adanya penambahan nilai karbon terikat, berat jenis bahan baku dan kemampuan kerekatan antar bahan.

Variasi nilai kalor dipengaruhi oleh kadar lignin dan zat ekstraktif, kadar lignin yang tinggi pada kayu 
akan mempengaruhi nilai kalor kayu tersebut, sedangkan kadar ekstraktif tergantung pada mudah dan tidak zat ekstraktif tersebut terbakar (Komarayati dan Gusmalina, 1994) serta Hudaya (1989) juga mengemukakan bahwa nilai kalor sangat dipengaruhi oleh kadar lignin dan zat ekstraktif. Kadar lignin yang tinggi akan meningkatkan nilai kalor hal ini terjadi pada briket kombinasi arang Ulin, Meranti, dan tempurung kelapa.

Sudrajat (1983) mengatakan bahwa bahan baku, bahan perekat, dan tekanan pengempaan sangat berpengaruh terhadap nilai kalor briket arang yang dihasilkan.

\section{KESIMPULAN DAN SARAN}

Dapat disimpulkan bahwa Nilai kalor tunggal berkisar antara $4.087 \mathrm{cal} / \mathrm{gr}$ s.d. $5.419 \mathrm{cal} / \mathrm{gr}, 2$ (dua) kombinasi campuran berkisar antara $4.039 \mathrm{cal} / \mathrm{gr} \mathrm{s.d.} 4.868 \mathrm{cal} / \mathrm{gr}$ dan 3 (tiga) kombinasi campuran $4.783 \mathrm{cal} / \mathrm{gr}$. Disarankan limbah moulding kayu yang mempunyai berat jenis kayu rendah dikombinasikan dengan kayu berat jenis kayu tinggi, batubara dan tempurung kelapa. 


\section{DAFTAR PUSTAKA}

Alpian. 2003. Pengaruh Komposisi Serbuk Arang Kayu Limbah Industri Kayu Lapis dan Kayu Limbah HTI terhadap Kualitas Briket Arang dengan Perekat Tepung Tapioka. Magister IImu Kehutanan. Samarinda.

Dinas Perkebunan Provinsi Kaltim. 2004. Statistik Perkebun. Dinas Perkebunan Provinsi Kaltim Samarinda.

Direktorat Jenderal Listrik dan Energi Baru. 1991. Pemilihan Jenis Pohon Energi. Direktorat Jenderal Listrik dan energi Baru. Departemen Pertambangan dan Energi. Jakarta.

Haspiadi. 2007. Laporan Penelitian Minimisasi Kandungan Sulfur Batubara dengan Proses Kimia untuk Bahan Baku Briket Batubara.

Hudaya. N dan Hartoyo, W. Made. 1989. Hasil Distilasi Kering dan Nilai Kalor dari Beberapa jenis Kayu HTI. Proceedings Diskusi Sifat dan Kegunaan Jenis Kayu HTI. Badan Litbang Kehutanan. Departemen Kehutanan. Jakarta.

Ishlah T. 2004. Hasil Evaluasi Konservasi Sumber Daya Mineral Tahun Anggaran 2004. http://www.dim.esdm.go.id/index.php. Dirjen Mineral, Departemen Energi dan Sumber Daya Mineral. Jakarta.

Sembiring FS. 2009. Pasokan Briket Batubara Diperkirakan Tak Cukupi Kebutuhan 2006. http://www.kapalangi.com/h/0000094770. Dierjen Mineral, Batubara dan Panas Bumi Departemen Energi dan Sumber Daya Mineral. Jakarta.

Sudrajat. 1983. Pengaruh Bahan Baku, Jenis Perekat, dan Tekanan Kempa terhadap Kualitas Briket Arang. Laporan No. 165. Pusat Penelitian dan Pengembangan Hasil Hutan Bogor. Bogor.

Komarayati dan Gusmailina. 1994. Pembuatan Arang dan Briket Arang dari Kayu Manis (Cinnamomum burmanii Ness ex. BL) dan Kayu Sukun (Artocarpus altilis Parkinson). Jurnal Penelitian Hasil Hutan Vol 12 No. 6.Badan Pengkajian dan Penerapan Teknologi. Jakarta.

Komunitas Bangun Pertama. 2007. Analisis Daampak Lingkungan Hidup. Rencana Kegiatan Penambangan Batubara. Kalimantan Timur.

Setiadji B,. 2006. Makalah Pengolahan Buah Kelapa Terpadu. Balai Pengkajian Teknologi Pertanian. Samarinda

Suroto HS dan Yuliansyah. 2008. Kombinasi Campuran Limbah Moulding Dan Kayu Hti Untuk Pellet Kayu Sebagai Bahan Bakar Alternatif. Jurnal Riset Teknologi Industri Vol 2 No. 3. Balai Riset dan Standardisasi Industri. Samarinda. 